\title{
ARTIFICIAL CRYPTORCHIDISM AND FERTILITY IN THE RABBIT
}

\author{
J. M. GUMMINS* AND T. D. GLOVER \\ Unit of Reproductive Biology, University of Liverpool
}

(Received 1st Fanuary 1970)

\begin{abstract}
Summary. Artificial cryptorchidism produced sterility in male rabbits within 7 days. Progressive infertility, which first appeared on the 2 nd day after operation, resulted from a failure of a normal number of live motile spermatozoa to fertilize. Many such spermatozoa had not discarded their cytoplasmic droplets, and it is thought that these were heat-affected and incapable of fertilization. This is because fertilization rate and implantation rate were significantly $(P<0.001)$ correlated with the number of live (droplet-free) spermatozoa in the inseminates.

There were no adverse effects on the ability of embryos to implant or to survive gestation, and the morphology and sex ratio of foetuses at term were normal. Before fertilization failure became apparent, there were significant $(P<0.001)$ improvements in embryonic survival rates and a theory is advanced to explain these findings.
\end{abstract}

\section{INTRODUCTION}

Artificial cryptorchidism is known to cause aspermatogenesis in laboratory animals (Fukui, 1923; Moore, 1924; Lawrence, 1926; Cunningham, 1927; Mori, 1951; El Azab, 1966), and it is likely that this is primarily due to an increase in testicular temperature. The operation also has an adverse influence on the morphology and motility of epididymal and ejaculated spermatozoa, and this has been shown in the rabbit (Glover, 1958; El Azab, 1966), the rat (Mori, 1951) and the guinea-pig (Lawrence, 1926). In the rabbit, it has been reported to be accompanied by a rapid loss of fertility (Knaus, 1932; Asdell \& Salisbury, 1941; Igboeli \& Foote, 1967, 1969), though no detailed attempt appears to have been made to relate quantitative changes in the semen picture resulting from artificial cryptorchidism to corresponding effects on fertility. This work is an attempt to produce such a correlation and uses, as criteria of fertility, the ability of spermatozoa to reach and to fertilize ova, and the capacity of any fertilized ova to undergo normal embryogenesis.

Experiment design

\section{MATERIALS AND METHODS}

Mature, line-bred, individually caged, New Zealand White rabbits, main-

* Present address: Department of Obstetrics and Gynecology, Vanderbilt University, Nashville, Tennessee, U.S.A. 
tained on a diet of SG1 pellets (Nutrients Ltd, Liverpool) were used throughout. Forty-two adult males, each weighing over $3.5 \mathrm{~kg}$, provided semen for fertility trials involving artificial insemination in a total of twenty-six groups, each of which consisted of seven virgin females. Animals that failed to ovulate were not included in the final data, which were based on 164 females only.

Preliminary data on semen quality were obtained from all males, before any fertility trials were carried out and appraisal was then continued on individual and pooled samples throughout the experiments. An initial experiment using a group of six of the bucks tested the fertility of semen ejaculated before artificial cryptorchidism ('normal' semen samples) and also on the 1st, 4th and 7th days following operation. It was found that fertility was lost by 7 days and data for the intermediate days were subsequently obtained using further groups of four to six bucks. These groups were also used to provide additional control material (see Table 1).

TABLE 1

DISTRIBUTION OF FERTILITY TRIALS

\begin{tabular}{|c|c|c|c|c|c|c|c|c|c|c|c|c|c|}
\hline \multirow{3}{*}{$\begin{array}{l}\text { Male group } \\
\text { ( four to six) } \\
\text { Total of forty-two } \\
\text { animals }\end{array}$} & \multirow[b]{2}{*}{ Normal } & \multicolumn{12}{|c|}{ Days after artificial cryptorchidism } \\
\hline & & 1 & 2 & 3 & & 4 & & 5 & & 6 & & & 7 \\
\hline & $F R \quad E V$ & $F R \quad E V$ & $F R \quad E V$ & $F R E$ & & $q R$ & & $F R E$ & $E V$ & $F R$ & $E V$ & $F R$ & $E V$ \\
\hline $\begin{array}{l}\mathbf{A} \\
\mathbf{B} \\
\mathbf{G} \\
\mathbf{D} \\
\mathbf{E} \\
\mathbf{F} \\
\mathbf{G} \\
\mathbf{H}\end{array}$ & $\begin{array}{ll}+ & i \\
+ & + \\
\dot{1} & + \\
\dot{1} & \dot{1}\end{array}$ & 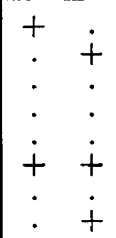 & 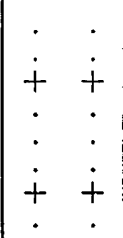 & 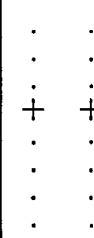 & & $\begin{array}{ll}+ & i \\
\cdot & i \\
\cdot & i \\
\cdot & i \\
\cdot & i\end{array}$ & & $\begin{array}{l}: \\
\dot{+}+ \\
:\end{array}$ & & $\begin{array}{l}\dot{+} \\
\dot{\dot{t}} \\
\dot{\dot{y}} \\
\dot{.}\end{array}$ & $\begin{array}{l}\dot{ } \\
+ \\
\dot{+} \\
\dot{5}\end{array}$ & $\begin{array}{l}+ \\
\dot{5} \\
\dot{ } \\
\dot{5} \\
\dot{.}\end{array}$ & $\begin{array}{l}\dot{+} \\
: \\
\dot{ } \\
:\end{array}$ \\
\hline $\begin{array}{l}\text { otal no. of } \mathrm{f} \\
\text { seminated }\end{array}$ & $21 \quad 28$ & $14 \quad 21$ & $14 \quad 14$ & 7 & & 7 & & 7 & 7 & 7 & 7 & 7 & 7 \\
\hline
\end{tabular}

+ , Insemination of seven females for estimation of fertilization rate (FR) or embryonic viability (EV) (see text).

\section{Operative procedure}

Males were anaesthetized with intravenous pentobarbitone sodium (Nembutal, $60 \mathrm{mg} / \mathrm{ml}$, Abbott Laboratories Ltd). Through a mid-ventral incision, the testes were drawn along the inguinal canals into the abdominal cavity and anchored to the abdominal wall by means of a suture taken through the inverted tunica vaginalis (Glover, 1958). Recovery was uneventful and libido appeared to be unaffected.

This operation was carried out on the same day in all the bucks of any one group.

\section{Assessment of fertility}

Semen was collected by means of an artificial vagina (Holborn Surgical Instrument Co., London) from adult males which had been selected for their high quality semen. Ejaculates were collected at 2- to 3-day intervals and after removal of any 'gel', the samples were examined at room temperature, both 
individually and after pooling. Motility was scored on a subjective scale of 0 to 6 , and the concentration of spermatozoa was estimated using a haemocytometer. Aliquots of the pooled semen were mixed with aqueous nigrosin-eosin for $5 \mathrm{~min}$, as recommended by Campbell, Dott \& Glover (1956), and then smeared on to clean glass slides. Percentages of 'live' and 'dead' (eosinophilic) spermatozoa and of different morphological types were estimated from counts of duplicate smears of each pooled sample.

Each doe in a group of seven was brought into post-pseudopregnant oestrus by means of an intravenous injection of 25 i.u. luteinizing hormone ( $\mathrm{LH}$, Pregnyl, Organon Laboratories), 19 to 21 days before insemination. Each was inseminated per vaginam with a $1-\mathrm{ml}$ aliquot of pooled semen, which had been diluted to $25 \times 10^{6}$ spermatozoa/ml with Ringer solution (Mann, 1964), and an ovulation-inducing injection of $\mathrm{LH}$ was given at the same time.

Each group of females was used for an estimation of either fertilization rate (FR) or embryonic viability (EV). When possible, animals in one FR and in one EV group were inseminated at the same time with aliquots from the same pooled semen samples (see Table 1); this procedure was an attempt to reduce variations due to differences between male groups.

\section{Fertilization rate}

FR females were killed 48 to $60 \mathrm{hr}$ after insemination; the numbers of ovulation points on the ovaries were recorded and each oviduct was flushed with 3 to $5 \mathrm{ml}$ of Ringer solution. Ova obtained were mounted on slides under vaselinesupported cover-slips and examined under phase-contrast microscopy. The occurrence of regular cleavage was taken to indicate fertilization and, when possible, this was confirmed by observation of the nuclei of the daughter blastomeres in ova which had been fixed in acetic alcohol (Chang, 1952), stained in acetocarmine (Darlington \& La Cour, 1962; Tesh, 1968) and mounted in $45 \%$ acetic acid. The presence or absence of polar bodies and of spermatozoa in the mucin layer, the zona pellucida or the perivitelline space was also noted.

\section{Embryonic viability}

Ten days after insemination, EV females were subjected to mid-ventral laparotomy under halothane (Fluothane, ICI Ltd) and nitrous oxide anaesthesia. If the animals were pregnant, the number, size and position of implantation sites were noted and pregnancy was allowed to continue. At Day 29 of pregnancy, just before term, the animals were killed and the uterine contents were examined. The position, orientation and weight of live and dead foetuses, the number of resorptions and placentae were all recorded, along with the sex of the live foetuses and any gross abnormalities. If it is assumed that the number of corpora lutea is the same as the number of ova originally released, then it is possible to estimate the implantation rate as the total number of implantation sites expressed as a percentage of the number of corpora lutea. Data on the normal development of rabbit foetuses have been given by Adams $(1960 \mathrm{a}, \mathrm{b})$, and from a knowledge of the number of embryos alive at various stages of pregnancy, it is possible to estimate the survival rate of foetuses between those stages. 


\section{RESULTS}

For convenience, the 'day' of the semen refers to the time elapsing between operation and the day of semen collection; thus '2-day spermatozoa' are those ejaculated by rabbits that have been artificially cryptorchid for 2 days.

\section{Fertilization rate (Table 2)}

The first significant decrease in FR occurred when 2-day spermatozoa were inseminated and, as the period of cryptorchidism increased, the number of eggs showing normal cleavage decreased rapidly to zero by 6 days. The first sign of infertility was a partial failure of fertilization with individual females, and total failure became apparent as early as 3 days after artificial cryptorchidism.

TABLE 2

POOLED ESTIMATES OF FERTILIZATION RATE

\begin{tabular}{l|c|c|c|c|c|c|c|c}
\hline & & \multicolumn{7}{|c}{ Days after artificial cryptorchidism } \\
\cline { 2 - 9 } & Normal & 1 & 2 & 3 & 4 & 5 & 6 & 7 \\
\hline No. of FR groups & 3 & 2 & 2 & 1 & 1 & 1 & 1 & 1 \\
No. of females & $19 \dagger$ & $13 \dagger$ & $11 \dagger$ & 7 & 7 & $6 \dagger$ & 7 & 7 \\
Ovulation points & 210 & 153 & 129 & 88 & 83 & 72 & 86 & 59 \\
Ova recovered & 159 & 123 & 95 & 71 & 66 & 52 & 74 & 37 \\
Abnormally cleaved & & & & & & & & \\
ova & 0 & 1 & 1 & 1 & 2 & 3 & 3 & 0 \\
Normally cleaved ova & 157 & 117 & 78 & 19 & 14 & 5 & 0 & 0 \\
Fertilization rate (\%) & $98 \cdot 7$ & $95 \cdot 1$ & $82 \cdot 1^{*}$ & $26 \cdot 8^{* *}$ & $21 \cdot 2^{* *}$ & $9 \cdot 6^{* *}$ & 0 & 0 \\
\hline
\end{tabular}

Significance of difference from controls: $* 0.05>P>0.001, * * 0.01>P$. † One or more females failed to ovulate.

There appeared to be an increased incidence of abnormally cleaving, fertilized ova associated with insemination of deficient semen, and spermatozoa were occasionally seen around the zona pellucida of uncleaved ova as late as 6 days.

Embryonic viability (Table 3 )

Adams (1960a, b), in a study of prenatal mortality in the rabbit, divided gestation into four main periods; namely pre-implantation, and early (up to 10 days), middle (10 to 17 days) and late (17 to 28 days) post-implantation. In the present work, however, since fertilization failure occurred so soon, data on post-implantation embryonic loss or survival was bound to be limited and, therefore, such a detailed analysis did not seem to be justified. Accordingly, the 'middle' and 'late' post-implantation periods have been pooled and are collectively called 'Iate'. Table 3 presents EV within the various stages of pregnancy; each estimate of survival is based on the difference between the successive sets of data, namely number of corpora lutea, total number of implantation sites, 'normal' 10-day blastocysts (which according to Adams are those of $12 \mathrm{~mm}$ diameter or more), and live 29-day foetuses. This method of calculation helps to allow for variations in the number of females due either to death during pregnancy or to loss of whole litters at some stage. 
Preliminary analysis of the data (Cochrane, 1943) revealed that $20 \%$ to $40 \%$ of the variance that existed was binomial in nature and analysis of variance was therefore carried out on unweighted percentages of the survival rates within individual litters, converted into angles (Fisher \& Yates, 1963). Variance was primarily due to the treatment of the male groups; in other words, differences in response between male and between female groups were not significant and it

TABLE 3

POOLED ESTIMATES OF EMBRYONIC VIABILITY

\begin{tabular}{l|c|c|c|c|c|c|c|c}
\hline & \multirow{6}{*}{} & \multicolumn{7}{|c}{ Days after artificial cryptorchidism } \\
\cline { 2 - 9 } & Normal & 1 & 2 & 3 & 4 & 5 & 6 & 7 \\
\hline No. of EV groups & 4 & 3 & 2 & 1 & 1 & 1 & 1 & 1 \\
\hline
\end{tabular}

Pre-implantation survival $=$ implantation rate

\begin{tabular}{l|c|c|c|c|c|c|c|c}
\hline No. of females & $24 \dagger$ & $16 \dagger$ & $13 \ddagger$ & $6 \S$ & 7 & 7 & 7 & 7 \\
Total implants & 196 & 129 & 129 & 8 & 40 & 1 & 2 & 0 \\
Corpora lutea & 260 & 167 & 149 & 64 & 95 & 80 & 85 & 67 \\
Survival (\%) & $75 \cdot 4$ & $77 \cdot 3$ & $86 \cdot 6$ & $12 \cdot 5 * *$ & $42 \cdot 1 *$ & $1 \cdot 3 * *$ & $2 \cdot 4 * *$ & $0 * *$ \\
\hline
\end{tabular}

Early embryonic survival: implantation to 10 days

\begin{tabular}{l|c|c|c|c|c|c|c|c}
\hline No. of females & 23 & 14 & $23 \ddagger$ & 3 & 6 & 1 & 2 & 0 \\
10-day implants & 172 & 126 & 113 & 7 & 38 & 1 & 1 & 0 \\
Total implants & 196 & 129 & 124 & 8 & 40 & 1 & 2 & 0 \\
Survival (\%) & $87 \cdot 8$ & $97 \cdot 7 * *$ & $91 \cdot 1$ & $87 \cdot 5$ & $95 \cdot 0$ & $100 \cdot 0$ & $50 \cdot 0$ & - \\
\hline
\end{tabular}

Late embryonic survival: 10 to 29 days

\begin{tabular}{l|c|c|c|c|c|c|c|c}
\hline No. of females & $21 \ddagger$ & 14 & $11 \ddagger$ & 3 & 6 & 1 & 1 & 0 \\
Live foetuses & 88 & 111 & 42 & 3 & 27 & 0 & 0 & 0 \\
10-day implants & 166 & 126 & 99 & 7 & 38 & 1 & 1 & 0 \\
Survival (\%) & $53 \cdot 0$ & $88 \cdot 1^{*}$ & $42 \cdot 4$ & $42 \cdot 9$ & $71 \cdot 1$ & 0 & 0 & - \\
\hline
\end{tabular}

Significance of difference from controls: $* 0.05>P>0.01, * * 0.01>P$.

$\dagger$ One or more females failed to ovulate.

\$ Female died in pregnancy, hence eliminated from subsequent survival estimate(s).

$\$$ Abnormal uterus, eliminated from data.

was considered justifiable to pool the data within 'days', as in Table 3. A complete analysis of variance is not included in these results because the data present such a striking picture, and where in Table 3 , degrees of significance of difference from the normal data are indicated, they have been calculated on ranked percentages for individual litters using the Mann-Whitney non-parametric U-test, corrected where necessary for tied data (Goldstein, 1964).

It is apparent from Table 3 that infertility in the EV females was mainly due to implantation failure and that there were no adverse effects on EV. On the 
contrary, when Day-1 semen was tested, there were significant and consistent improvements in both early and late survival rates, as compared to the normals. This resulted in a significantly higher $(P<0.001)$ mean litter size at term, of $8.07 \pm 1.69$ compared to $4 \cdot 63 \pm 2 \cdot 41$. Control litter sizes were smaller than those reported by Adams $(1960 \mathrm{a}, \mathrm{b})$ and this apparent improvement in fertility might be regarded as spurious. But analysis of variance of the data in the four control EV groups, as well as in the three 1-day EV groups, revealed no significant within-day variations and it must be concluded that the evidence for increased fertility on Day 1 is statistically sound. It is also interesting that Day-2 semen produced no change in the implantation rate, despite the fact that the FR in females inseminated with the same semen (Tables 1 and 2) was significantly reduced. This might be interpreted cautiously as representing a decrease in the number of fertilized ova lost before implantation.

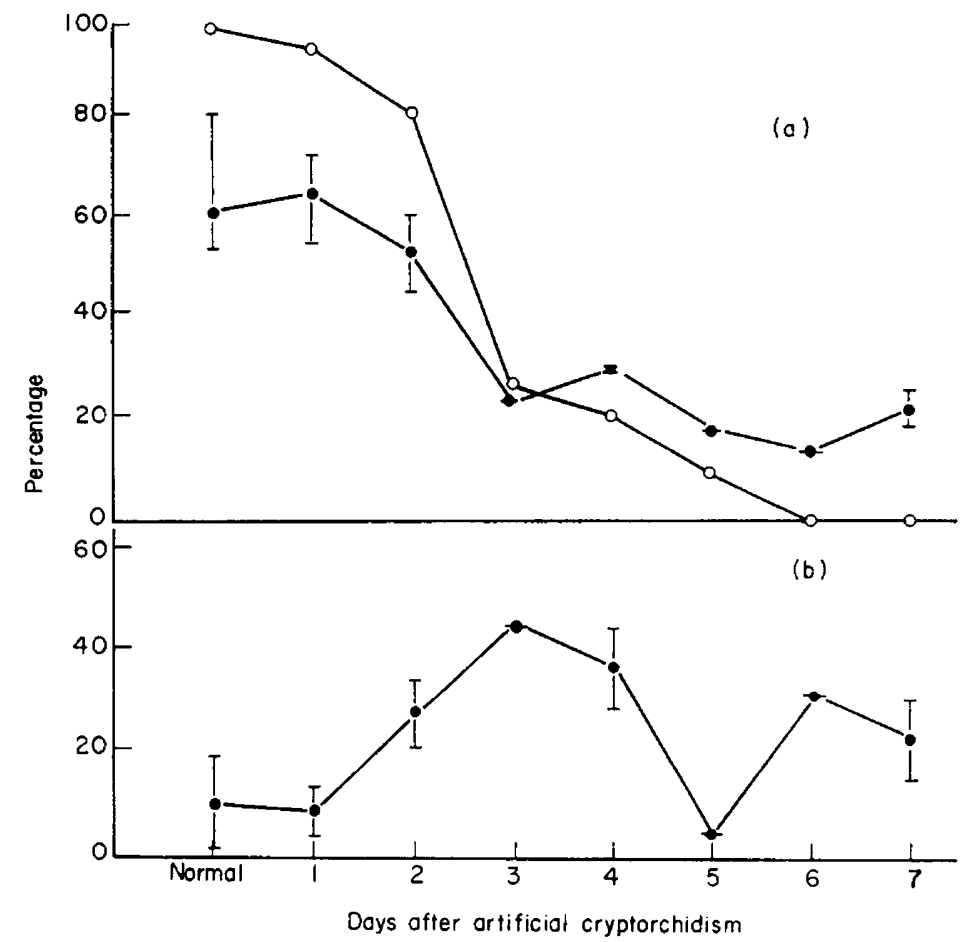

Text-Fig. 1. (a) Percentage of live, normal spermatozoa (9); mean and range of estimates on pooled samples of semen. $O$, FR. (b) Percentage of live spermatozoa with retained cytoplasmic droplets; mean and range of estimates on pooled samples of semen.

In all, 133 live, normal, male foetuses were recorded out of a total of 247 $(48.54 \%)$, and chi-squared analysis failed to show any significant within-day variations from a 50:50 sex ratio. The overall mean foetal weight was $43.54 \pm$ $7 \cdot 20 \mathrm{~g}$ and variations between litters were such that no meaningful trends could be detected. There was a negative correlation between the number of foetuses in a litter and the mean weight of those foetuses. However, unlike the observations of Hammond (1934) and Tesh (1968, 1969), this was not statistically 
significant ( $r=-0.0136,45$ d.f.). The orientation of live foetuses at term appeared to be random; $43 \%$ faced towards, and $57 \%$ away from the cervix.

No teratogenic effects could be detected resulting from the insemination of semen from artificially cryptorchid rabbits; thirteen foetuses were found to have abnormalities of the parietal bones. However, these occurred in control as well as in experimental EV groups and were all offspring of the same male group (C, see Table 1).
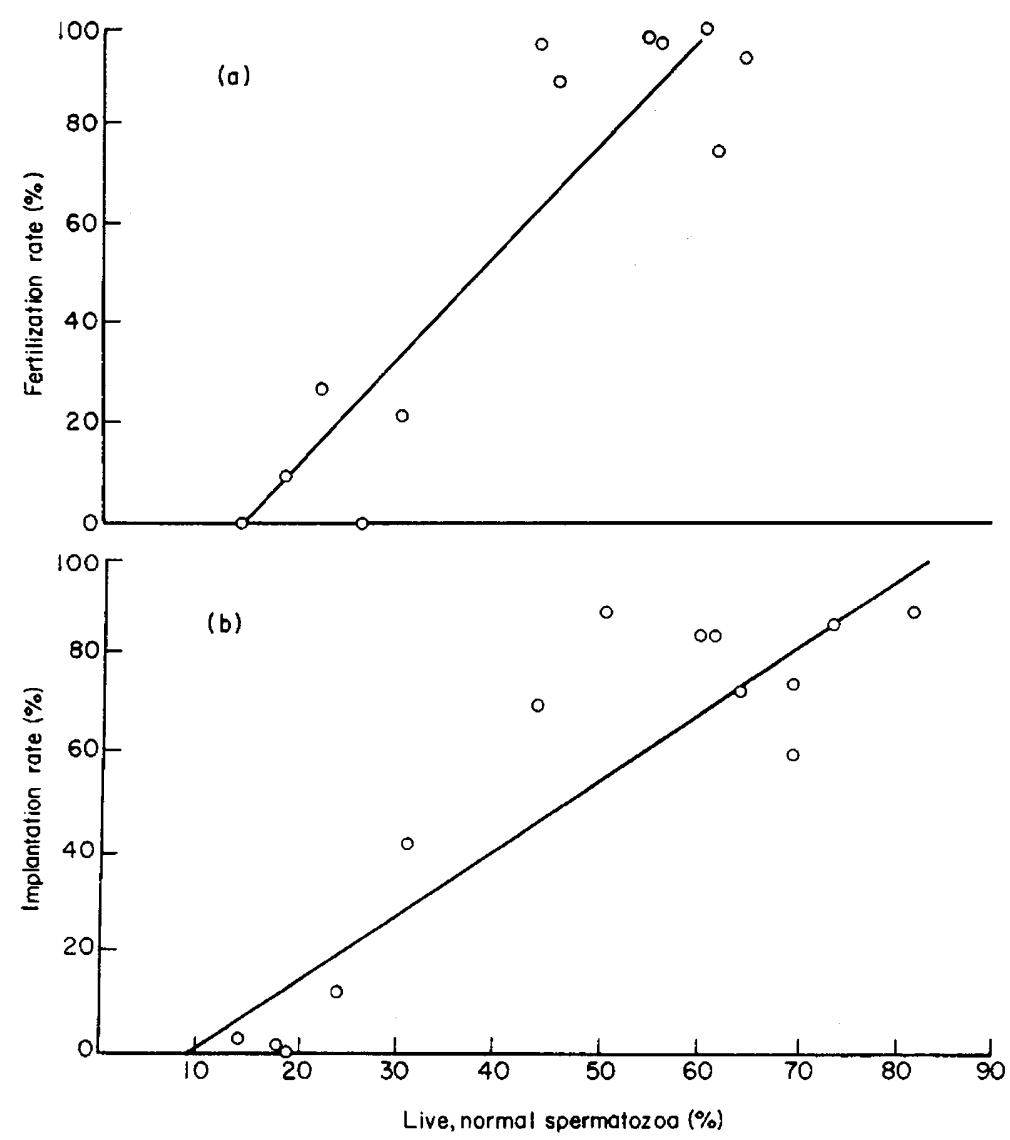

TexT-Fig. 2. (a) Regression of FR upon the percentage of live normal spermatozoa inseminated. $O$, mean for one FR group of females. $r=0.9055, \mathrm{~N}=12, P<0.001, \mathrm{~b}$ y $/ \mathrm{x}=$ $2 \cdot 1250$. (b) Regression of implantation rate upon the percentage of live, normal spermatozoa inseminated. $O$, mean for one EV group of females. $r=0.8602, \mathrm{~N}=14, P<0.001$, b $y / x=1.3184$.

\section{Number of ovulations}

Analysis of variance of the numbers of ovulation points or corpora lutea per female revealed no significant variations between any of the experimental groups. This means that either criterion can equally well be taken to represent the number of ova released and also that a certain amount of direct comparison between the estimates of FR and EV is justified. The mean number of ovulation sites or corpora lutea was $11 \cdot 26 \pm 2 \cdot 73(\mathrm{~N}=164)$. 
Semen characteristics

The first quantitative indication of change in semen quality occurred on Day 2, with an increase in the proportion of live spermatozoa with retained distal (end of mid-piece) cytoplasmic droplets (Text-fig. 1b and Pl. 1, Fig. 1). These forms were invariably motile and did not shed the droplet even after several hours in vitro; the droplet frequently appeared to be expanded and tended to distort the mid-piece of the spermatozoon. Normally, the cytoplasmic droplet is discarded from the end of the mid-piece at ejaculation and, in fact, the best indicator of changing fertility was found to be the incidence of live, morphologically normal, droplet-free spermatozoa (Text-fig. 1a). Text-fig. 2 shows two scatter diagrams of FR and implantation rate respectively, plotted against the percentage of live, morphologically normal spermatozoa used for each group of females. Although the spread of the data tends to exaggerate the closeness of the correlations, they are both highly significant and similar to one another in slope of regression $(P<0.001)$; this means that changes in implantation rate associated with changes in semen quality closely paralleled changes in FR.

The overall live-dead ratios in nigrosin-eosin smears and estimations of the motility of spermatozoa showed a gradual decline in the quality of ejaculates over the 7-day period of study. However, these criteria could not be directly related to loss of fertility. On Day 7, for example, when the animals were completely sterile, ejaculates still contained a mean of $43 \%$ live cells, and were accredited a mean motility score of 3 . On the other hand, increased percentages of abnormal spermatozoa, such as those with coiled tails and fragmented forms (Pl. 1, Fig. 2), did not occur until the 6 th or 7 th day.

\section{DISCUSSION}

This work has shown that rapid and progressive infertility resulting from artificial cryptorchidism appears primarily as a failure in fertilization. The onset of infertility is not due to any change in the incidence of live motile spermatozoa, although there is a highly significant correlation between FR and a reduced proportion of live, 'normal' spermatozoa in inseminates. The term 'normal' is used here with reference to those actively motile spermatozoa that have discarded the cytoplasmic droplet. Probably, therefore, live spermatozoa that retain the droplet in vitro not only indicate incipient seminal degeneration but may themselves be 'senescent' types with reduced, or lost, fertilizing competence.

It is well recognized that, in the mammalian epididymis, the cytoplasmic droplet migrates along the mid-piece of a spermatozoon during the process of so-called sperm maturation. The droplet is normally discarded during ejaculation and this suggests that its function, if indeed it serves one at all, concerns the life of a spermatozoon only within the male tract. This is supported by the identification of lysosomal enzymes in the cytoplasmic droplets of ram and bull spermatozoa, for there has been speculation that shedding of the droplet may be important in enabling the gamete to survive in a free state (Dott \& Dingle, 1968). The present results are the first experimental demonstration of a definite association between the failure of some spermatozoa to discard their cytoplasmic droplets and a distinct deficiency in seminal function. At present, it is impossible 


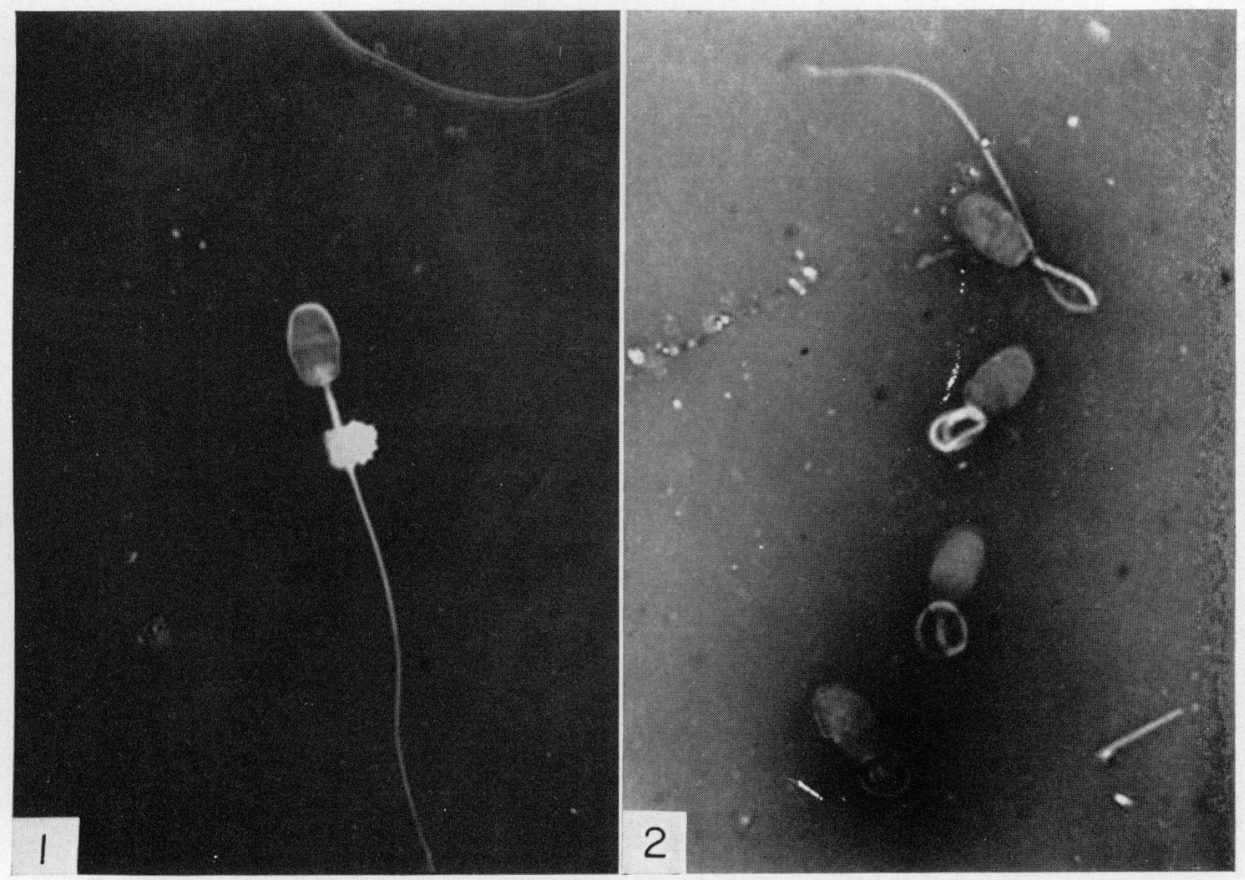

Nigrosin eosin smears, $\times 1000$.

lin. 1. Eosinophobic, live spematozoon with distal cyoplasmic droplet; 2 days of artificial ryptorchidism.

lis: 2. Eosinophilie dead spermatozoa with coiled tails: 8 days of artificial eryptorehidism. 
to say whether, following artificial cryptorchidism, retention of the droplet in live spermatozoa is a primary manifestation of intrinsic degenerative change in the spermatozoa, or whether it is a more complex response to a change in milieu within the epididymis.

It is interesting that fertility, in terms of foetal survival, appeared to be significantly improved after 1 day of artificial cryptorchidism. Salisbury \& Flerchinger (1967) noticed a similar transient increase in the fertility of bull semen stored in vitro, and postulated that spermatozoa with 'aberrant chromatin' were the first to lose their fertilizing competence under these conditions. Even assuming that the reduced embryonic losses noted in the present work were due to a particular loss of fertilizing ability on the part of some spermatozoa, it is difficult to see how the genetic content of a spermatozoon could in itself influence the ability of the cell to withstand adverse environmental conditions, such as those imposed by artificial cryptorchidism. A possible explanation is that the oldest spermatozoa are the first to lose fertilizing competence, having probably suffered the most cytoplasmic and nuclear damage due to wear and tear.

It is known that rabbit spermatozoa take 9 to 12 days to pass through the epididymis (Koefoed-Johnsen, 1961) and there is evidence that considerable mixing occurs during this transit (Orgebin-Crist, 1965). It is probable, therefore, that the sperm population within the cauda epididymidis consists of cells with widely differing chronological ages. Observations in the bull (De Groot, 1961) and in the guinea-pig (Young \& Simeone, 1930; Simeone \& Young, 1931) have also indicated that 'ageing' of spermatozoa may become apparent within the epididymis before ejaculation. Artificial cryptorchidism did not appear to reduce the ability of spermatozoa to induce normal embryogenesis. This fact contrasts interestingly with the results of 'ageing' spermatozoa in the cauda epididymidis at scrotal temperatures. When migration of 'young' forms is prevented by ligation of the corpus epididymidis, the fertility of spermatozoa stored in the cauda is not lost for 28 to 49 days (Hammond \& Asdell, 1926; Igboeli, 1968; Paŭfler \& Foote, 1968; Tesh, 1968; Tesh \& Glover, 1969), and furthermore, adverse effects on the viability of embryos are apparent before any decrease in the fertilizing ability of the spermatozoa. Similar patterns of functional change are known to accompany the storage of spermatozoa in vitro and irradiation of semen (Salisbury, 1965; Lanman, 1968). These indicate that sperm chromatin is not stable for an indefinite period but is susceptible to a slow degenerative change. Such change may show itself by death of implanted embryos. However, in artificial cryptorchidism, it is possible that the fertilizing ability of spermatozoa is so rapidly lost that any latent or actual genetic damage that might occur is masked. In this connection, it is noteworthy that when spermatozoa are 'aged' fairly quickly in the uterus of the rabbit, it appears to be the fertilizing capacity that is first affected (Hammond \& Asdell, 1926; Tesh, $1968,1969)$. It is tempting to consider that abdominal temperature might be the detrimental cause in both conditions but so many differences exist between the environments in the male and female tracts that, at this stage, the idea can only be conjectural. It is more likely that fertilization failure in both situations results from a stereotyped response of spermatozoa to fairly severe adverse environments 
and does not necessarily reflect the action of a common factor. The present results suggest that one early effect of artificial cryptorchidism may be the inhibition of fertilizing capacity in chronologically 'old' spermatozoa. This would increase the probability of ova being fertilized by genetically sound gametes and, thus, initially improve fertility. However, even if this be true, there will be a rapid loss of fertility as the number of competent spermatozoa drops below the threshold needed for sperm-ovum contact.

At all events, there is little doubt that early loss of fertility following artificial cryptorchidism is due to a failure of sperm penetration rather than sperm transport. This contrasts with the suggestion made by Asdell \& Salisbury (1941) and will be discussed in more detail elsewhere.

\section{ACKNOWLEDGMENTS}

We are grateful to the Population Council for financial support. Thanks are also due to Professor M. R. Sampford, of the University of Liverpool, for statistical advice, to Mr W. Lee for the photography and to Mrs G. P. Boyd for technical assistance.

\section{REFERENCES}

AdAms, G. E. (1960a) Studies on prenatal mortality in the rabbit Oryctolagus cuniculus: the amount and distribution of loss before and after implantation. F. Endocr. 19, 325.

Adams, G. E. (1960b) Prenatal mortality in the rabbit Oryctolagus cuniculus. F. Reprod. Fert. 1, 36.

AsDell, S. A. \& SAlisbury, G. W. (1941) The viability of spermatozoa in the abdominal epididymis and the failure of motile sperms to fertilize ova. Am. $\mathcal{F}$. Physiol. 132, 791.

Campeell, R. G., DotT, H. M. \& Glover, T. D. (1956) Nigrosin-eosin as a stain for differentiating live and dead spermatozoa. F. agric. Sci., Camb. 48, 1.

Ghang, M. G. (1952) Fertilizability of rabbit ova and the effects of temperature in vitro on their subsequent fertilization and activation in vivo. F. exp. Zool. 121, 351.

Cochrane, W. G. (1943) Analysis of variance for percentages based on unequal numbers. F. Am. statist. Ass. 38, 287.

CunnInghaM, J. T. (1927) Experiments on artificial cryptorchidism and ligature of the vas deferens in mammals. Br. F. exp. Biol. 4, 333.

Darington, C. D. \& LA Cour, L. F. (1962) The handling of chromosomes, 4th edn. Allen and Unwin, London.

DE Groot, B. (1961) Ageing of bull sperms at the end of the passage through the epididymis. F. Reprod. Fert. 2, 107.

Dotr, H. M. \& Dingle, J. T. (1968) Distribution of lysosomal enzymes in the spermatozoa and cytoplasmic droplets of bull and ram. Expl Cell Res. 52, 523.

EL-AZAB, E. A. (1966) Effect of local application of heat to the scrotum on spermatogenesis, maturation of the spermatozoa in the epididymis, and semen quality in rabbits and bulls. Dissertation, Tierärztl. Fak., Ludwig-Maximiliens-Univ., München.

Fisher, R. A. \& YATEs, F. (1963) Statistical tables for biological, agricultural and medical research, 6th edn. Oliver \& Boyd, London.

Fukur, N. (1923) Action of body temperature on the testicle. Japan med. Wld, 3, 160.

Glover, T. D. (1958) Experimental induction of seminal degeneration in rabbits. Stud. Fert. 10, 80.

Goldstern, A. (1964) Biostatistics; an introductory text. Macmillan, New York.

HAMmond, J. (1934) The fertilization of rabbit ova in relation to time. A method of controlling the litter size, the duration of pregnancy and the weight of the young at birth. F. exp. Biol. 11, 140.

Hammond, J. \& Asdell, S. A. (1926) The vitality of the spermatozoa in the male and female reproductive tracts. Br. F. exp. Biol. 4, 155.

IGBOELI, G. (1968) Bull and rabbit testes and epididymal spermatozoa at normal and body temperatures studied with the aid of ligatures. Diss. Abstr. 29B, 346.

Igroen, G. \& Foote, R. H. (1967) Semen quality after surgical cryptorchidism. 7. Anim. Sci. $26,875$.

Igboeli, G. \& Foote, R. H. (1969) Changes in epididymal spermatozoa and in the testis of rabbits after experimental cryptorchidism. F. exp. Zool. 170, 489. 
KNaus, H. (1932) Zur Physiologie der Spermatozoen. Arch. Gynaek. 151, 302.

KoEFOED-Johnsen, H. H. (1961) Om epididymis' function. I. Spermiernes passagehastighed gennem epididymis. Aersberetn. Inst. Sterilitetsforskn. K. Vet-og Landbohojsk (Kbh), p. 57.

Lanman, J. T. (1968) Delays during reproduction and their effects on the embryo and fetus. New Engl. F. Med. 278, 993.

LAWRENCE, W. (1926) The fate of the germinal epithelium of experimental cryptorchid testes of guinea pigs. Biol. Bull. mar. biol. Lab., Woods Hole, 51, 129.

Mann, T. (1964) The biochemistry of semen and of the male reproductive tract, 2nd edn. Methuen, London.

MOORE, C. R. (1924) Properties of the gonads as controllers of somatic and physical characteristics. VI. Testicular reactions in experimental cryptorchidism. Am. F. Anat. 34, 269.

Morr, A. (1951) Studies on the abnormal spermatozoa. I. Appearance of abnormal spermatozoa in the experimental cryptorchidism of albino rats. Tohoku f. agric. Res. 2, 15.

Orgebin-Crist, M.-G. (1965) Passage of spermatozoa labelled with thymidine- ${ }^{3} \mathrm{H}$ through the ductus epididymidis of the rabbit. F. Reprod. Fert. 10, 241.

PAứpler, S. K. \& Foote, R. H. (1968) Morphology, motility and fertility of spermatozoa recovered from different areas of ligated rabbit epididymides. F. Reprod. Fert. 17, 125.

Salisbury, G. W. (1965) Aging phenomena in gametes. A Review. F. Geront. 20, 281.

SAlisbury, G. W. \& Flerchinger, F. H. (1967) Ageing phenomena in spermatozoa. I. Fertility and prenatal losses with use of liquid semen. F. Dairy Sci. 50, 1675.

Simeone, F. A. \& Young, W. G. (1931) A study of the function of the epididymis. IV. The fate of nonejaculated spermatozoa in the genital tract of the male guinea-pig. F. exp. Biol. 8, 163.

Tеsн, J. M. (1968) Some effect of ageing in spermatozoa on fertilization and prenatal development in the domestic rabbit, Oryctolagus cuniculus. Ph.D. thesis, University of Liverpool.

TEsH, J. M. (1969) Effects of the ageing of rabbit spermatozoa in utero on fertilization and prenatal development. F. Reprod. Fert. 20, 299.

Tesh, J. M. \& GLover, T. D. (1969) Ageing of rabbit spermatozoa in the male tract and its effect on fertility. F. Reprod. Fert. 20, 287.

Young, W. C. \& Simeone, F. A. (1930) Development and fate of spermatozoa in the epididymis and vas deferens in the guinea-pig. Proc. Soc. exp. Biol. Med. 27, 838. 